\title{
Transatlantica
}

Revue d'études américaines. American Studies Journal

\section{Armand Mattelard et Erik Neveu. Introduction aux Cultural Studies.}

Paris : La Découverte, 2003, 122p. 7.95 E.

\section{Michel Imbert}

\section{(2) OpenEdition}

\section{Journals}

Édition électronique

URL : http://journals.openedition.org/transatlantica/829

DOI : $10.4000 /$ transatlantica.829

ISSN : 1765-2766

Éditeur

AFEA

\section{Référence électronique}

Michel Imbert, « Armand Mattelard et Erik Neveu. Introduction aux Cultural Studies. », Transatlantica [En ligne], 1 | 2005, mis en ligne le 22 avril 2006, consulté le 29 avril 2021. URL : http://

journals.openedition.org/transatlantica/829 ; DOI : https://doi.org/10.4000/transatlantica.829

Ce document a été généré automatiquement le 29 avril 2021.

\section{c) (i) $\odot$}

Transatlantica - Revue d'études américaines est mis à disposition selon les termes de la licence Creative Commons Attribution - Pas d'Utilisation Commerciale - Pas de Modification 4.0 International. 


\title{
Armand Mattelard et Erik Neveu. Introduction aux Cultural Studies.
}

Paris : La Découverte, 2003, 122p. 7.95 E.

\author{
Michel Imbert
}

1 Cet ouvrage retrace en cinq chapitres la génèse et le développement d'un courant de recherche jusqu'à un certain point méconnu en France. Dans les années 60, l'école de Birmingham (Centre for Contemporary Cultural Studies) a élargi la notion de culture au sens noble du terme en accordant aux styles de vie de la classe ouvrière et aux médias l'attention jusque là réservée à la culture des lettrés.

2 Le premier chapitre évoque les travaux des pères fondateurs: le retentissement profond de l'ouvrage de Richard Hoggart, The Uses of Literacy (1957), l'influence non moins marquante de Culture and Society de Raymond Williams (1958), qui décrivait le rôle salvateur assigné à la culture par un Matthew Arnold ou un F.R Leavis, enfin, l'étude d'Edward P.Thomson, The Making of the English Working Class (1963), qui fit date dans l'histoire sociale. L'engagement de ces chercheurs dans la Nouvelle Gauche est souligné ainsi que leur position relativement marginale dans le monde universitaire.

Le second chapitre décrit la floraison des Cultural Studies à partir de 1964, la façon dont l'intérêt pour la vie quotidienne de la classe ouvrière a fait progressivement tache d'huile en s'étendant aux sous-cultures jeunes, puis à la question du "genre " masculin/féminin et à celle du racisme. La culture n'y est jamais appréhendée indépendamment des enjeux de pouvoir mais comme un processus de résistance à des stratégies d'hégémonie. Cette approche interdisciplinaire se situe à la croisée des influences théoriques les plus diverses (le marxisme d'Althusser, la sémiologie de Barthes, la sociologie de l'école de Chicago, entre autres), comme en témoigne la réflexion novatrice de Stuart Hall.

Dans les années 80, marquées en Grande-Bretagne par le tournant conservateur, l'intérêt s'est déplacé vers la réception des médias par divers publics et la construction d'une identité individuelle recomposée à partir de ses appartenances multiples (classe, race, genre, nation...). 
5 Le quatrième chapitre retrace l'internationalisation des Cultural Studies déjà fortement implantées en Grande-Bretagne dans les polytechnics et l'Open University, leur influence croissante dans les départements d'université aux Etats-Unis et en Amérique latine, l'inflation de revues s'y rattachant dans les années 90 . Cette expansion mondiale s'est accompagnée d'une fragmentation de la recherche et d'un certain désengagement politique.

6 Pour conclure, les auteurs soulignent la prédilection actuelle de ces études pour les objets-fétiches de l'industrie culturelle (comme la poupée Barbie ou Madonna) et s'interrogent sur les conditions d'un renouveau du «matérialisme culturel», notamment dans le domaine des études postcoloniales.

7 Le mérite de cette " introduction » est de baliser un champ foisonnant et d'esquisser en termes clairs l'évolution historique d'une «anti-discipline» parfois confuse. Les nombreuses références au fil du texte et la bibliographie sélective en fin d'ouvrage témoignent d'un remarquable souci de synthèse.

INDEX

Thèmes : Recensions

\section{AUTEUR}

MICHEL IMBERT

Université de Paris VII - Denis Diderot 